\begin{tabular}{|l|l|l|}
\hline \multicolumn{2}{|c|}{ PublisherInfo } \\
\hline \hline PublisherName & $:$ & BioMed Central \\
\hline \hline PublisherLocation & $:$ & London \\
\hline \hline PublisherImprintName & $:$ & BioMed Central \\
\hline \hline
\end{tabular}

\title{
Binding of surfactant proteins A and D
}

\begin{tabular}{|l|l|l||}
\hline \multicolumn{2}{|c|}{ ArticleInfo } \\
\hline \hline ArticleID & $:$ & 1643 \\
\hline \hline ArticleDOI & $:$ & $10.1186 /$ rr-2001-68575 \\
\hline \hline ArticleCitationID & $:$ & 68575 \\
\hline \hline ArticleSequenceNumber & $:$ & 54 \\
\hline \hline ArticleCategory & $:$ & Paper Report \\
\hline \hline ArticleFirstPage & $:$ & 1 \\
\hline \hline ArticleLastPage & $:$ & 4 \\
\hline \hline & & RegistrationDate : 2001-9-19 \\
\hline ArticleHistory & $:$ & Received \\
\hline ArticleCopyright & $:$ & Biomed Central Ltd2001 \\
\hline \hline ArticleGrants & $:$ & \\
\hline \hline ArticleContext & $:$ & 129312211 \\
\hline \hline
\end{tabular}


Jeff Hoyt, ${ }^{\text {Aff1 }}$

Corresponding Affiliation: Aff1

Aff1 Department of Veterans Affairs, USA

\section{Keywords}

EDHFCD14, LPS binding, pulmonary inflammatory response to pathogens, surfactant protein A, surfactant protein D

\section{Introduction}

Surfactant proteins A (SP-A) and D (SP-D) are glycoprotein constituents of lung surfactant and are innate components of the immune system of the lung. Both proteins bind rough LPS, which is a component of bacteria that is contained in cigarettes and in a variety of dusts, and CD14. But SP-A and SP-D interact with CD14 in different manners. The authors examine the structural differences between the two proteins and how these differences influence binding with LPS and CD14.

\section{Comments}

Lipopolysaccharide (LPS) has been hypothesized to play an important role in a variety of lung disorders, including occupational lung diseases, asthma and COPD. The authors of this study have investigated the interactions of lung surfactant proteins with the LPS-receptor CD14 and with LPS. Individual structural characteristics of each surfactant protein have been determined to play important roles in both CD14 and LPS binding. Rough LPS was used in this study and reference to other work is given for smooth LPS. This study demonstrates that lung surfactant proteins can bind to LPS and alter binding to the LPS receptor CD14. The authors speculate that investigating these interactions will aid in the understanding of the molecular basis of pathogen induced inflammation in lungs.

\section{Methods}


The authors cloned and overexpressed SP-A, SP-D and CD14 proteins by conventional molecular biology methods to obtain sufficient protein for their study.

LPS and CD14 binding to SP-A and SP-D was studied using ELISA assays with anti-SP-A IgG or anti SP-D IgG and horseradish peroxidase-labeled secondary antibody.

Sucrose density centrifugation was used to examine the interaction of rough LPS with SP-A and CD14.

\title{
Results
}

The interaction of SP-A and SP-D with rough LPS depends on calcium and the lectin properties of these proteins and the carbohydrate-recognition region (CRD) of SP-A is involved in rough LPS binding. Both SP-A and SP-D were found to bind CD14 in a concentration dependent manner but the mode of binding differs. SP-A interaction with CD14 does not require calcium and may not depend on the lectin property of SP-A. SP-D interaction with CD14 does require calcium and may depend on the lectin property of SP-D. Surface determinants in or near the neck region of SP-A are involved in the interaction with CD14, while for SP-D the CRD is required for interaction with CD14. SP-A binds to deglycosylated CD14 while SP-D does not bind. This suggests that SP-A binds to the peptide portion of CD14 while SP-D binds to the carbohydrate portion. Both SP-A and SP-D were found to have distinctly different effects upon the interaction of LPS with CD14.

\section{Discussion}

The authors demonstrate that SP-A and SP-D bind LPS and CD14 by different mechanisms. The differences in binding demonstrate that these lung proteins can alter LPS-CD14 interactions. SP-A and SP-D interactions with CD14 may well play a critical role in the modulation of pulmonary inflammatory response.

\section{Additional information}

\author{
Additional references:
}

There is another interesting paper by Sano et al (J Immunol 1999, 163:387-395) 


\section{References}

1. Sano H, Chiba H, Iwaki D, Sohma H, Voelker DR, Kuroki Y: Surfactant proteins A and D bind CD14 by different mechanisms. J Biol Chem. 2000, 275: 22442-22451.

This PDF file was created after publication. 